\title{
Amorphous $\mathrm{Eu}_{0.9} \mathrm{Ni}_{0.1} \mathrm{~B}_{6}$ Nanoparticles for Formaldehyde Vapor Detection
}

De Li Xiang, a,b Shu Mei Hou, ${ }^{a, b}$ Dong Ge Tong a,b*

${ }^{a}$ State Key Laboratory of Geohazard Prevention and Geoenvironment Protection, Chengdu University of Technology, Chengdu 610059, China. E-mail: tongdongge@163.com; Fax: +862884073193.

${ }^{\mathrm{b}}$ Collaborative Innovation Center of Panxi Strategic Mineral Resources Multi-purpose Utilization, College of Materials and Chemistry \& Chemical Engineering, Chengdu University of Technology, Chengdu 610059, China.

Summary: 10 Pages; Experimental section; 3 Figures and 4 Tables 


\section{Experimental Section}

\subsection{Preparation of $\mathrm{Eu}_{0.9} \mathrm{Ni}_{0.1} \mathrm{~B}_{6}$ nanoparticles}

All reagents were used as received. In a typical synthesis, $\mathrm{EuCl}_{3}(9 \mathrm{mmol})$ and $\mathrm{NiCl}_{2} \cdot 6 \mathrm{H}_{2} \mathrm{O}(1 \mathrm{mmol})$ were added into a plasma reactor, which has been reported in our previous work, ${ }^{3,22}$ containing $[\mathrm{BMIM}]\left[\mathrm{BF}_{4}\right](20 \mathrm{~mL})$ at $25{ }^{\circ} \mathrm{C}$ under argon with stirring. Then, $1 \mathrm{mmol}$ sodium phosphite and boroethane $\left(5 \mathrm{mLmin}^{-1}\right)$ were introduced. The reaction was carried out for 40 min under plasma at an electric field of $500 \mathrm{~V} \mathrm{~cm}^{-1}$. The as-prepared sample was sequentially washed with deionized water and three washings with alcohol. Finally, the product was dried at $60{ }^{\circ} \mathrm{C}$. To synthesize other samples with different $\mathrm{Ni}$ dopants, a total amount of $10 \mathrm{mmol}$ of $\mathrm{EuCl}_{3}$ and $\mathrm{NiCl}_{2}$ with various molar ratios of $\mathrm{Eu} / \mathrm{Ni}$ was applied.

\subsection{Characterization}

X-ray diffraction (XRD) patterns were determined using a diffractometer (Rigaku $\mathrm{D} / \mathrm{max}-\mathrm{rA}, \mathrm{Cu} \mathrm{K} \alpha$ radiation at $40 \mathrm{kV}, 70 \mathrm{~mA}$ ). Eu, $\mathrm{Ni}$ and $\mathrm{B}$ contents were confirmed by inductively coupled plasma atomic emission spectroscopy (ICP-AES, Irris, Avantage). Transmission electron microscopy (TEM) images and selected-area electron diffraction (SAED) patterns were obtained by a Carl Zeiss Libra200 microscope. The specific surface areas were tested by the Brunauer-Emmett-Teller (BET) method (Bjbuilder SSA-6000). X-ray photoelectron spectroscopy (XPS; Perkin-Elmer PHI 5000C ESCA, Al Ka radiation) equipped with an in situ XPS sample pool was used to evaluate the surface electronic states. After drying in an argon atmosphere, the sample was transferred to an analysis chamber, and the XPS spectrum was recorded. The XPS depth profiles were determined using a $\mathrm{Cs}^{+}$sputter beam $(0.5 \mathrm{keV}, 45 \mathrm{nA})$ in an area of $300 \mathrm{~mm} \times 300 \mathrm{~mm}$. The corresponding elemental composition analyses were performed using the Ion-Spec software. Time-of-flight secondary ion mass spectrometry (ToF-SIMS) experiments were carried out using the PHI TRIFT II (USA) equipment. The spectra were recorded in a mass range of 1-280 $\mathrm{Da}\left(\mathrm{Ga}^{+}\right.$source). Water droplet contact angle and free surface energy of $\mathrm{Eu}_{1-\mathrm{x}} \mathrm{Ni}_{\mathrm{x}} \mathrm{B}_{6}$ nanoparticles were measured by using a surface energy determination system 
(DMO-901FE, Kyowa, Japan). The film surface roughness $\left(\mathrm{R}_{\mathrm{a}}\right)$ of $\mathrm{Eu}_{1-\mathrm{x}} \mathrm{Ni}_{\mathrm{x}} \mathrm{B}_{6}$ nanoparticles sensing film was determined using Profilm3D (Filmetrics, USA ).

\subsection{Gas sensing measurements}

The HCHO (dry standard gas, NiuRuiDe Special Gas Co. Ltd.) detection experiments were carried out at room temperature using a HW-30A static test system (HanWei Electronics Co. Ltd.). Herein, the response of our capacitive sensors is defined as the ratio of the capacitance changes $(\Delta C)$ of the capacitive sensor in the presence of analyte $\left(\mathrm{C}_{\text {analyte }}\right)$ to its capacitance in the absence of analyte $(\mathrm{C})$. It can be expressed as follows: Response $=\Delta \mathrm{C} / \mathrm{C}=\left(\mathrm{C}_{\text {analyte }}-\mathrm{C}\right) / \mathrm{C}(1)$. The times of response and recovery are defined as the sensors achieve ninety percent change of total capacity variation.

For the fabrication of the capacitive sensor, an appropriate amount of $\mathrm{EuB}_{6}$ was blended with ethanol to make a homogeneous mixture and then spread over a commercial interdigitated electrode (IDE). After the volatilization of ethanol, the fabricated sensors were pre-burned at $80{ }^{\circ} \mathrm{C}$ for $72 \mathrm{~h}$ in an electric vacuum drying oven. During the evaluation period, argon was applied as a carrier gas. Then, the formaldehyde was thinned to the necessary concentrations by argon, which was monitored by mass flow controllers. 
Table S1 The effect of molar ratio of $\mathrm{EuCl}_{3} / \mathrm{NiCl}_{2} \cdot 6 \mathrm{H}_{2} \mathrm{O}$ on the structure, morphology, phase composition, specific surface areas and average size of the obtained products.

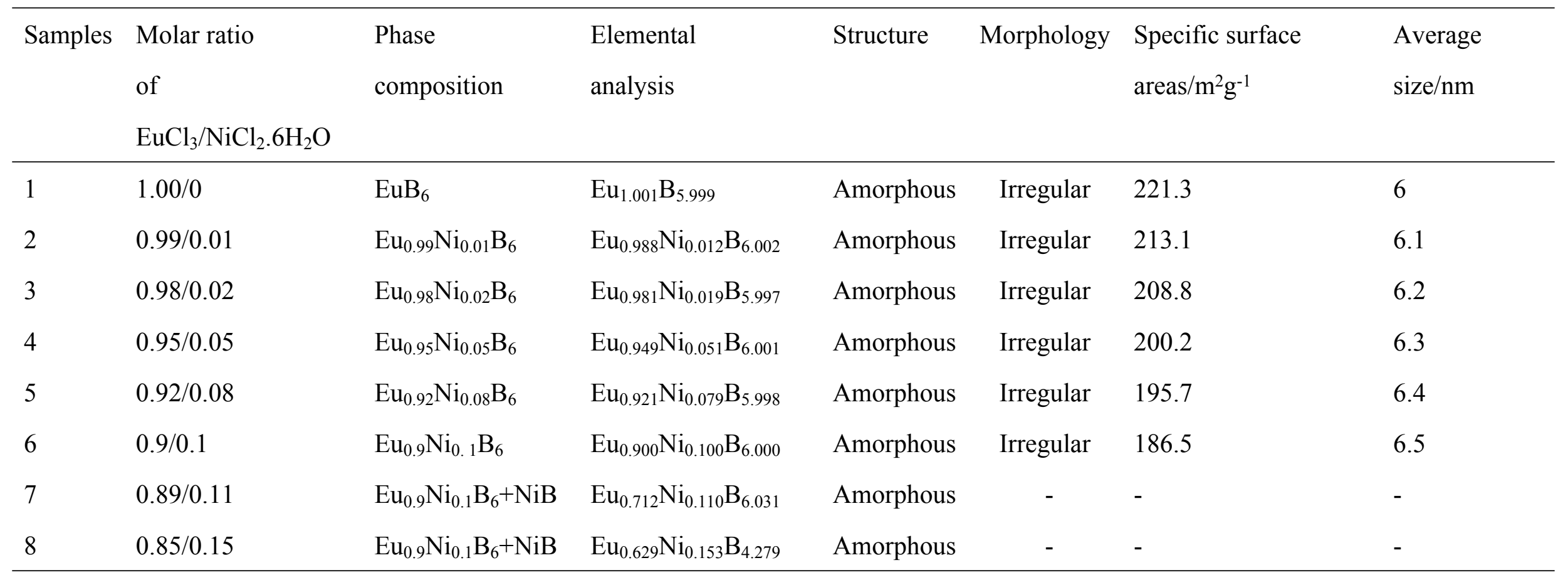


Table S2 The average size and specific surface areas of the samples

\begin{tabular}{lllll} 
Samples & Structure & Morphology & Specific surface areas $/ \mathrm{m}^{2} \mathrm{~g}^{-1}$ & Average size $/ \mathrm{nm}$ \\
\hline $\mathrm{Eu}_{0.9} \mathrm{Ni}_{0.1} \mathrm{~B}_{6}$ obtained at $723 \mathrm{~K}$ & Amorphous+Crystalline & Irregular & 80.9 & 100 \\
$\mathrm{Eu}_{0.9} \mathrm{Ni}_{0.1} \mathrm{~B}_{6}$ obtained at $923 \mathrm{~K}$ & Crystalline & Irregular & 30.3 & 1000 \\
$\mathrm{Eu}_{0.9} \mathrm{Ni}_{0.1} \mathrm{~B}_{6}$ obtained at $1023 \mathrm{~K}$ & Crystalline & Irregular & 14.2 & 1500 \\
\hline
\end{tabular}


Table S3 Room temperature HCHO sensing performance of $\mathrm{Eu}_{0.9} \mathrm{Ni}_{0.1} \mathrm{~B}_{6}$ in this work compared with previous work.

\begin{tabular}{|c|c|c|c|c|c|c|c|c|}
\hline Sensing materials & Concentration/ppm & Sensor type & $\begin{array}{l}\text { Defined } \\
\text { response }\end{array}$ & $\begin{array}{l}\text { Response } \\
\text { value }\end{array}$ & $\begin{array}{l}\text { Response/Recovery } \\
\text { time/s }\end{array}$ & $\begin{array}{l}\text { Detection } \\
\text { limit/ppb }\end{array}$ & $\begin{array}{l}\text { Anti-humidit } \\
\mathrm{y} / \%{ }^{*}\end{array}$ & Ref. \\
\hline $\mathrm{In}_{2} \mathrm{O}_{3} / \mathrm{MoS}_{2}$ & 50 & Resistive & $\begin{array}{l}\text { Resistance } \\
\text { variation ratio }\end{array}$ & $75.2 \%$ & $14 / 22$ & 200 & 33 & {$[1]$} \\
\hline Polyethyleneimine/SWCNTs & 0.4 & Acoustic & $\begin{array}{l}\text { Frequency } \\
\text { shifts }\end{array}$ & $12.1 \mathrm{kHz}$ & $47.3 / 58.6$ & 24 & 40 & {$[2]$} \\
\hline $\mathrm{EuB}_{6}$ & 10 & Capacitive & $\begin{array}{l}\text { Capacity } \\
\text { change ratio }\end{array}$ & $50.8 \times 10^{-4}$ & $23 / 30$ & 50 & 60 & {$[3]$} \\
\hline $\mathrm{VG} / \mathrm{SnO}_{2}$ & 5 & Resistive & $\begin{array}{l}\text { Resistance } \\
\text { variation ratio }\end{array}$ & $4.6 \%$ & $46 / 95$ & 20 & 10 & {$[4]$} \\
\hline ZIF-8/polyoxometalate & 100 & Photoconductive & $\begin{array}{l}\text { Photocurrent } \\
\text { change }\end{array}$ & $0.042 \mu \mathrm{A}$ & $15.1 / 16.2$ & 400 & 33 & {$[5]$} \\
\hline $\mathrm{GO} / \mathrm{MoS}_{2}$ & 10 & Resistive & $\begin{array}{l}\text { Resistance } \\
\text { variation ratio }\end{array}$ & $2.75 \%$ & $73 /-$ & - & - & {$[6]$} \\
\hline $\mathrm{GO} / \mathrm{TiO}_{2}$ & 0.5 & Resistive & $\begin{array}{l}\text { Resistance } \\
\text { variation ratio }\end{array}$ & 0.64 & $112 / 126$ & 100 & 0 & {$[7]$} \\
\hline
\end{tabular}




\begin{tabular}{|c|c|c|c|c|c|c|c|c|}
\hline $\mathrm{WO}_{3-\mathrm{X}} \mathrm{QDs}$ & 100 & Resistive & $\begin{array}{l}\text { Resistance } \\
\text { ratio }\end{array}$ & 1.6 & $150 / 120$ & 1500 & 20 & [8] \\
\hline $\mathrm{ZnO}$ nanofibers & 100 & Photoconductive & $\begin{array}{l}\text { Photocurrent } \\
\text { Ratio }\end{array}$ & 12.61 & $32 / 17$ & - & - & [9] \\
\hline Au@ZnO & 5 & Photoconductive & $\begin{array}{l}\text { Resistance } \\
\text { ratio }\end{array}$ & 10.57 & $138 / 104$ & - & 40 & {$[10]$} \\
\hline $\mathrm{ITO} / \mathrm{Cu}$ & 10 & Resistive & $\begin{array}{l}\text { Resistance } \\
\text { variation ratio }\end{array}$ & 11.78 & $25 / 30$ & - & 70 & [11] \\
\hline $\mathrm{TiO}_{2}$ nanotubes & 10 & Resistive & $\begin{array}{l}\text { Resistance } \\
\text { variation ratio }\end{array}$ & 6.5 & $180 /-$ & 40 & 40 & [12] \\
\hline $\mathrm{Eu}_{0.9} \mathrm{Ni}_{0.1} \mathrm{~B}_{6}$ & 10 & Capacitive & $\begin{array}{l}\text { Capacity } \\
\text { change ratio }\end{array}$ & $112.3 \times 10^{-4}$ & $15.3 / 14.2$ & 15 & 90 & $\begin{array}{l}\text { This } \\
\text { work }\end{array}$ \\
\hline
\end{tabular}

*Anti-humidity in this work refers to the relative humidity refers to the relative humidity which has litter effect on the response of sensing materials. 
Table $\mathrm{S} 4$ The surface roughness and surface free energy of $\mathrm{Eu}_{1-\mathrm{x}} \mathrm{Ni}_{\mathrm{x}} \mathrm{B}_{6}$

\begin{tabular}{llllllll}
\hline Samples & Ni dopant & Phase composition & Film thickness $/ \mathrm{nm}^{*}$ & $\mathrm{Ra} / \mathrm{nm}^{*}$ & $\gamma_{\text {total }} / \mathrm{mJm}^{-2 * *}$ & $\gamma_{\mathrm{np}} / \mathrm{mJm}^{-2 * *}$ & $\gamma_{\mathrm{p}} / \mathrm{mJm}^{-2 * *}$ \\
\hline 1 & 0 & $\mathrm{EuB}_{6}$ & 600 & 5.6 & 57.00 & 45.62 & 11.38 \\
2 & 0.01 & $\mathrm{Eu}_{0.99} \mathrm{Ni}_{0.01} \mathrm{~B}_{6}$ & 620 & 5.4 & 56.45 & 45.42 & 11.03 \\
3 & 0.02 & $\mathrm{Eu}_{0.98} \mathrm{Ni}_{0.02} \mathrm{~B}_{6}$ & 630 & 5.5 & 55.55 & 45.10 & 10.55 \\
4 & 0.05 & $\mathrm{Eu}_{0.95} \mathrm{Ni}_{0.05} \mathrm{~B}_{6}$ & 570 & 5.8 & 54.31 & 44.60 & 9.71 \\
5 & 0.08 & $\mathrm{Eu}_{0.92} \mathrm{Ni}_{0.08} \mathrm{~B}_{6}$ & 580 & 5.5 & 52.55 & 43.87 & 8.68 \\
6 & 0.1 & $\mathrm{Eu}_{0.9} \mathrm{Ni}_{0.1} \mathrm{~B}_{6}$ & 610 & 5.7 & 49.73 & 42.79 & 6.94 \\
\hline
\end{tabular}

* The film thickness and surface roughness $\left(\mathrm{R}_{\mathrm{a}}\right)$ measured from the sensing film of $\mathrm{Eu}_{1-\mathrm{x}} \mathrm{Ni}_{\mathrm{x}} \mathrm{B}_{6}$ nanoparticles;

** $\gamma_{\text {total }}$ is the total surface free energy equal to the sum of the nonpolar Lifshitz-van der Waals component $\gamma_{\mathrm{np}}$ and the polar component $\gamma_{\mathrm{p}}$. The contact angles of drops of glycerol and a-bromnaphthalene are also used to determine the three components of the surface free energy. 


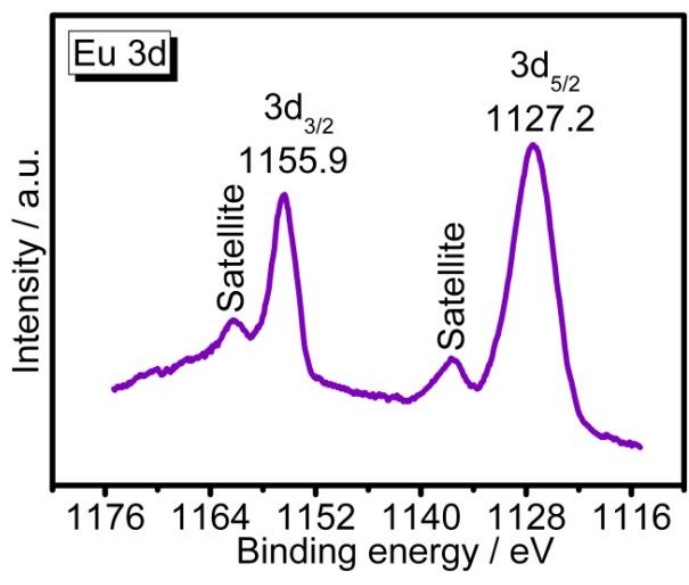

a

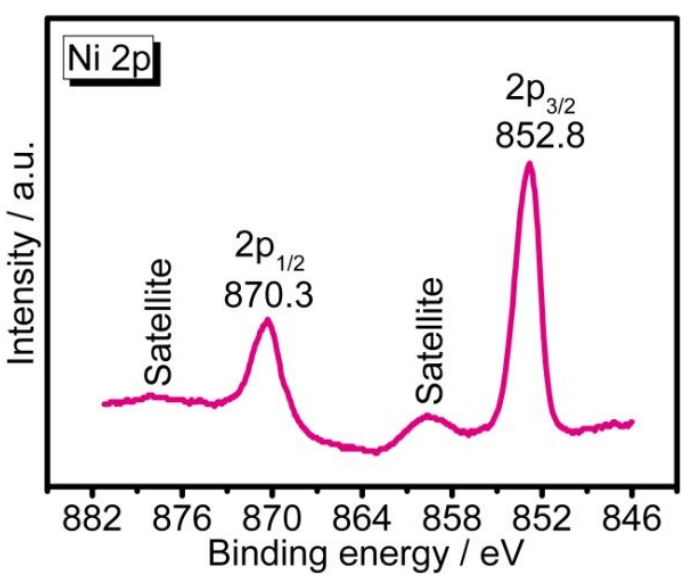

b

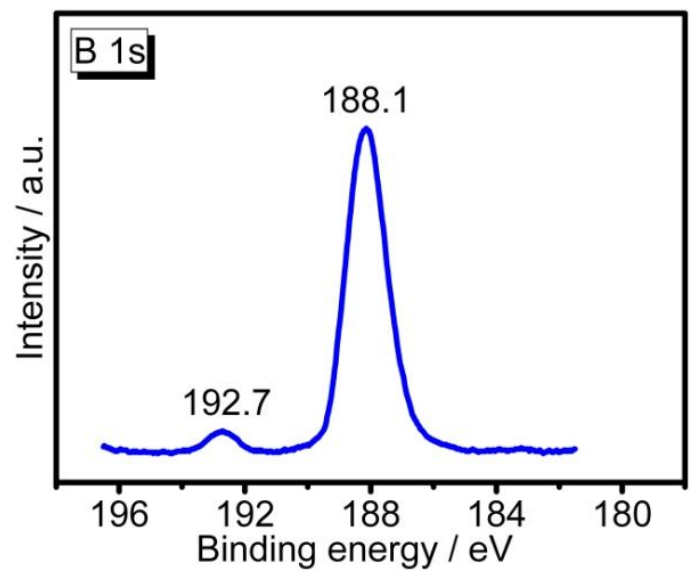

C

Fig. S1 (a) Eu 3d XPS; (b) Ni 2p XPS and (d) B 1s XPS spectra of the sample.

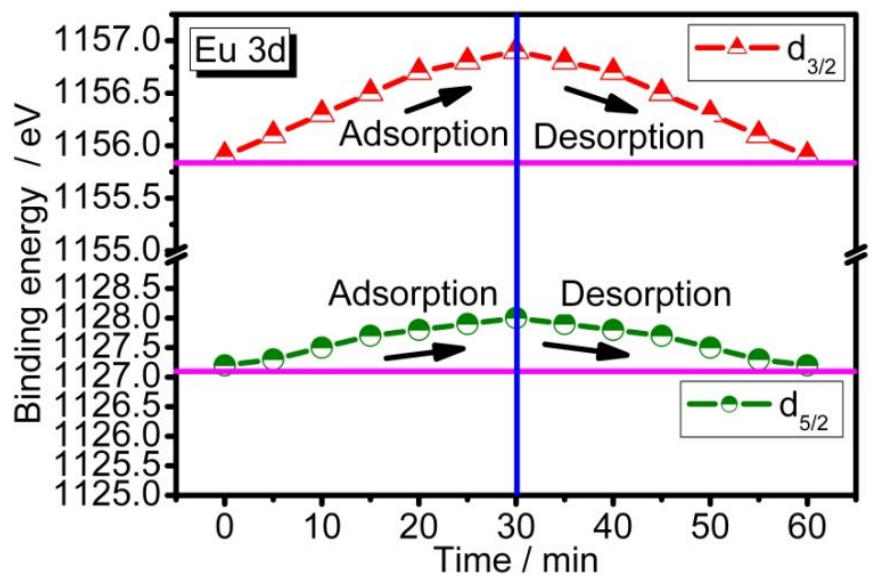

Fig.S2 The typical binding energy shifts of Eu3d of the sample during the adsorption and desorption over $\mathrm{HCHO}$ at room temperature. 


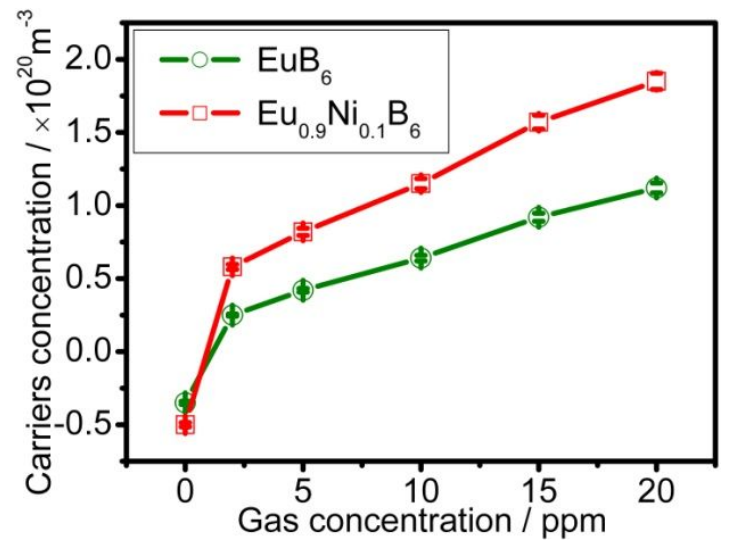

a

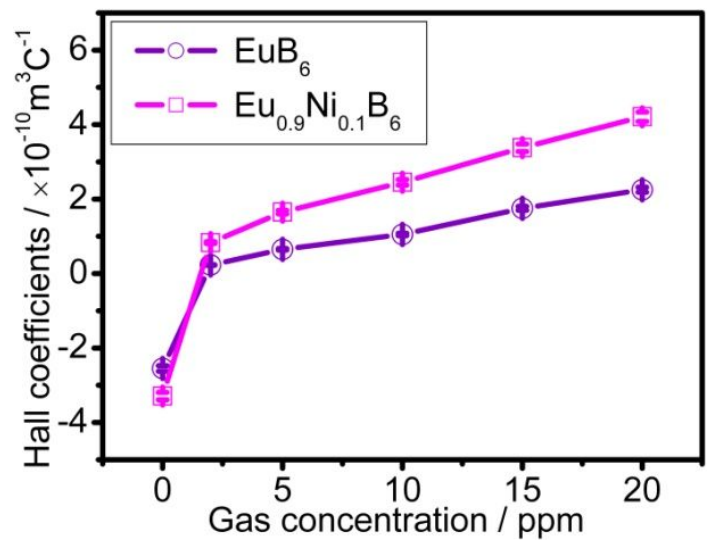

b

Fig.S3 The comparison of (a) Hall coefficients and (b) carrier concentration of the samples after adsorption of $\mathrm{HCHO}$ with different concentrations. 